\title{
SURGICAL TREATMENT OF STRESS URINARY INCONTINENCE USING A SIMPLE OPERATIVE PROCEDURE OF MESHPLASTY
}

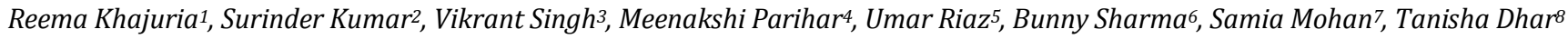

${ }_{1}^{1}$ Lecturer, Department of Obstetrics and Gynaecology, Government Medical College, Jammu.

${ }^{2}$ Associate Professor, Department of Obstetrics and Gynaecology, Government Medical College, Jammu.

${ }^{3}$ Assistant Professor, Department of General Surgery, Government Medical College, Jammu.

${ }^{4}$ Assistant Surgeon, Department of Obstetrics and Gynaecology, Government Medical College, Jammu.

5 Resident, Department of General Surgery, Government Medical College, Jammu.

${ }^{6}$ Resident, Department of General Surgery, Government Medical College, Jammu.

${ }^{7}$ Resident, Department of General Surgery, Government Medical College, Jammu.

${ }^{8}$ Resident, Department of General Surgery, Government Medical College, Jammu.

\section{ABSTRACT}

\section{OBJECTIVE}

Aim is to establish/evaluate the simplicity, effectiveness and safety of mesh plasty using polypropylene mesh in stress urinary incontinence. The treatment of stress urinary incontinence has undergone a revolution in recent years due to emergence on the market of suburethral slings.

\section{METHOD}

The present study was conducted on 52 patients who came in OPD of Department of Obstetrics and Gynaecology, SMGS Hospital, Govt. Medical College, Jammu, over the period of three years (Jan 2012 to Dec 2014) with clinical evidence of stress urinary incontinence with or without various degrees of genital prolapse or DUB. Patients were evaluated preoperatively by taking history, detailed general and systemic examination. Various clinical investigations were also done. A polypropylene mesh was placed at mid urethral level. Simultaneous repair of pelvic floor defect and/or vaginal hysterectomy was performed in the same sitting. Postoperative follow-up included physical examination and also assessing patient's satisfaction level.

\section{RESULTS}

No major complication occurred in intraoperative/postoperative period except for mesh erosion in one patient.

\section{CONCLUSION}

Meshplasty is relatively safe, simple, quick and cost effective surgical treatment for stress urinary incontinence.

\section{KEYWORDS}

Stress Urinary Incontinence, Meshplasty, Propylene Mesh.

HOW TO CITE THIS ARTICLE: Khajuria R, Kumar S, Singh V, et al. Surgical treatment of stress urinary incontinence using a simple operative procedure of meshplasty. J. Evolution Med. Dent. Sci. 2016;5(41):2503-2507, DOI: 10.14260/jemds/2016/584

\section{INTRODUCTION}

In normal urinary bladder the pressure in U. bladder does not increase with filling of urine, it is due to centrally mediated neuronal reflexes. The bladder outlet and urethra are closed at rest to maintain continence. During bladder emptying, there is decrease in urethral resistance followed by voluntary contraction of the bladder. The relaxation of urinary sphincter and pelvic floor muscles permit urine to flow into urethra. With rare exception the urinary incontinence occurs when pressure in urinary bladder increases than urethral resistance and urine flows involuntarily beyond urinary sphincter. Alteration in anatomy or function of bladder or urethra during storage/filling or emptying phases of urination may lead to urinary incontinence. Urinary incontinence due to poorly functioning urethra is called SUI.(1)

Financial or Other, Competing Interest: None.

Submission 15-01-2016, Peer Review 09-02-2016,

Acceptance 16-02-2016, Published 20-05-2016.

Corresponding Author:

Dr. Vikrant Singh,

H. No. 264, Sector No.-6,

Channi Himmat-180015,

Jammu.

E-mail: vikrant1118@rediffmail.com

DOI: $10.14260 / j e m d s / 2016 / 584$
Stress Urinary Incontinence (SUI) is defined as involuntary leak of urine due to increased intra-abdominal pressure without any rise in detrusor pressure that exceeds the pressure which urethral closure mechanism can withstand. Though it is not a life-threatening condition, but is a social and hygienic problem in peri- and post-menopausal women.(2) In majority of patients SUI is due to anatomic hypermobility of urethra, which leads to faulty urethral closure under stress and in few patients it may be because of intrinsic sphincter weakness. Although the aetiology of poor urethral function in stress incontinent females is not completely understood, but identifiable risk factors for this include pregnancy, childbirth, menopause, obesity and advanced age.

Women who had vaginal deliveries (Multiparous) are at higher risk of developing stress urinary incontinence than females who delivered by caesarean sections. Recent advances in mechanism of SUI show that the support at mid urethral level is weak resulting into sagging of mid urethra. So the weak and torn periurethral fascia is given support with synthetic material the polypropylene mesh for permanent solution for this problem of stress urinary incontinence. Stress in continence understanding has undergone evolution over time and also its management. Older methods for SUI treatment include Kelly's repair and abdominal bladder neck suspension surgeries. The newer techniques are the surgeries TVT (Tension free vaginal tape), TOT (Trans-obturator tape) and 
meshplasty. In meshplasty, the appropriate size of polypropylene (Prolene) mesh is placed at mid urethral level to prevent displacement of urethra along with its facial covers. With this the urethra remains closed during increased intraabdominal pressure. This mesh also provides support to mid urethra, which is similar mechanism on which TVT, TOT and TSUIT work.

\section{RISKS FOR URINARY INCONTINENCE \\ Age}

The prevalence gradually increases with age, but it steadily increases after age 65. The type of incontinence may differ by age; some studies suggest a higher prevalence of stress incontinence in women younger than 60 years and urge incontinence in older women.(2)

\section{Race}

Traditionally, Caucasian women are believed to have higher rates of urinary incontinence than women of other races.(3) It is not yet clear whether these differences are biologic, related to health care access or affected by cultural expectations and symptom tolerance thresholds. Since most of the studies have been conducted on Caucasian population, further studies of Non-Caucasian populations are needed. The authors urge women health care physicians around the globe to come forward in this direction.

\section{Obesity}

Increased Body Mass Index (BMI) is a significant and independent risk factor for SUI.(4) Evidence suggests that the prevalence of both urge and stress incontinence increases proportionately with BMI.(5) Theoretically, the increase in intra-abdominal pressure that coincides with an increased BMI results in a proportionally higher intravesical pressure, which overcomes urethral closing pressure and leads to incontinence.(6) Deitel reported a decline in the prevalence of SUI from 61 to 11\%, in 138 morbidly obese women following weight loss.(7)

\section{Menopause}

Few studies suggest an increase in urinary dysfunction after menopause.(8) However, in these separating hypo-estrogenic effects from the effects of aging is difficult. High-affinity oestrogen receptors have been identified in the urethra, pubococcygeal muscle and bladder trigone. Hypoestrogenic collagen changes and reductions in urethral vascularity and volume of skeletal muscle collectively may contribute to impaired urethral function via a decreased resting urethral pressure.(9)

\section{Childbirth and Pregnancy}

SUI is more in parous compared with nulliparous women. The effects of childbirth on incontinence may result from direct injury to pelvic muscles and connective tissue attachments and also nerve damage from trauma or stretch.(10)

\section{MATERIAL AND METHODS}

The present study was conducted in the Department of Obstetrics and Gynaecology, SMGS Hospital, Govt. Medical College, Jammu. In one of the units, 52 patients with complaint of stress urinary incontinence were treated surgically using the procedure of meshplasty. Majority of these patients had associated DUB or varying degrees of prolapse. Along with meshplasty, hysterectomy and/or AP repair was also done in these patients. All the patients were multiparous.

Majority patients were in the age group of 40 to 50 years. Youngest patient was 28 years and was P2. In all patients, a detailed history was taken followed by complete general physical examination and local examination. All the patients had clearly demonstrable stress incontinence. All the patients had positive Bonney's test. Urodynamic studies were not done due to technical reasons.

\section{OPERATIVE PROCEDURE}

All surgeries were done in lithotomy position. Anaesthesia depended upon the procedure to be done. Local anaesthesia, i.e. Xylocaine and Saline adrenaline infiltration $(1: 200,000) /$ spinal or general anaesthesia was used. Foley's catheter was used to define mid-urethra and also the bladder neck location. A polypropylene mesh of $3 \mathrm{~cm}$ by $1 \mathrm{~cm}$ was designed (From the mesh used in hernia repair). This was placed at mid urethra level after dissecting vagina from bladder. The mesh was anchored laterally to the pubovesicocervical fascia with 1-0 or 2-0 vicryl sutures. The fixation was done in a tension free manner by allowing a small forceps to be passed beneath it. Thereafter, the overlying vagina was closed with interrupted suture using 1-0 vicryl (Fig. 1).

In patients of DUB, NDVH (Non-Descent Vaginal Hysterectomy) was done first followed by meshplasty. In prolapsed patients, vaginal hysterectomy with meshplasty or AP repair with meshplasty was done. Foley's indwelling catheter was kept and removed after 24 to $48 \mathrm{hrs}$. The patients were given antibiotics as per hospital protocol (Cephalosporin). Patients were discharged from hospital on day 3 or 4 except those who were from far off places. At the time of discharge, patients were specially instructed to avoid strenuous activities and intercourse for at least six weeks.

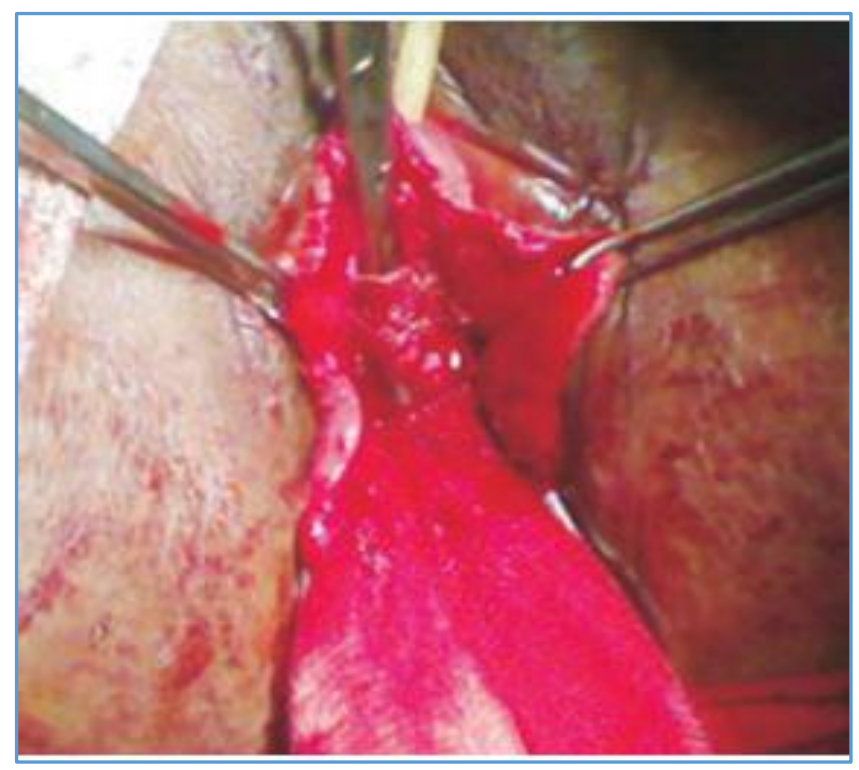

Fig: 1 Mesh at Mid Urethra Level

\section{FOLLOW-UP}

The patients were called up in Gynaecology OPD weekly for the first month and were evaluated for any urinary complaints. Urine routine examination was done in symptomatic patients. Subsequently, they were called at 6 weeks follow-up surgery 
to evaluate healing, assessment of any recurrence of symptoms (No urinary leak on coughing or straining).

\section{DISCUSSION}

Stress urinary incontinence, the complaint of involuntary leakage during effort or exertion occurs at least weekly in onethird of adult women. The basic evaluation of women with stress urinary incontinence includes a history, physical examination, cough stress test, voiding diary, post-void residual urine volume and urinalysis. Formal urodynamic testing may help guide clinical care, but whether urodynamics improves or predicts the outcome of incontinence treatment is not yet clear. The distinction between urodynamic stress incontinence associated with hypermobility and urodynamic stress incontinence associated with intrinsic sphincter deficiency should be viewed as a continuum rather than a dichotomy, of urethral function.

Initial treatment should include behavioural changes and pelvic floor muscle training. Oestrogen is not indicated to treat stress urinary incontinence. Bladder training, vaginal devices and urethral inserts also may reduce stress incontinence. Bulking agents reduce leakage, but effectiveness generally decreases after 1-2 years. Surgical procedures are more likely to cure stress urinary incontinence than nonsurgical procedures, but are associated with more adverse events. Based on available evidence at this time, colposuspension (Such as Burch) and pubovaginal sling (Including the newer mid-urethral synthetic slings) are the most effective surgical treatments.

As the population is aging, the medical community is increasingly challenged with the problem of urinary incontinence. More women (Prevalence of 31\% to 63\%) are affected than men.(11) Urinary incontinence can severely restrict patients in their daily activities and social life.

Medical advances in the prevention, diagnosis and treatment of urinary incontinence mean an improved quality of life for a large number of women.

Open colposuspension and conventional tape procedures are considered the most effective interventions for treating female Stress Urinary Incontinence (SUI) to date. Good longterm results have been reported for both interventions.(11) The TVT (Tension-Free Vaginal Tape) procedure is the most widely used technique for tape placement worldwide. The operation was first described by Ulmsten et al in 1996 and aims at restoring continence by placement of a monofilament polypropylene mesh under the mid-urethra.(12) Various complications have been reported in association with the TVT procedure including bladder perforation, voiding dysfunction, retropubic haematoma and injuries to structures of the true pelvis. A second generation of tapes has been applied using the trans-obturator approach, which was developed by Delorme.(13) and De Leval.(14) This approach avoids the retropubic space, thereby reducing the risk of inadvertent bladder and intestinal injury. Moreover, no adhesions are induced in the retropubic space, which could be important for the feasibility of future interventions. Trans-obturator tapes have since been established as the second tape procedure in addition to the TVT. $(15,16)$

Urethral sling surgeries to treat urinary incontinence involve placing a sling around the urethra to lift it back into a normal position and to exert pressure on the urethra to aid urine retention.
The sling material may be muscle, ligament or tendon tissue taken from the woman or from an animal such as a pig. It may also be composed of synthetic material such as plastic that is compatible with body tissues or of absorbable polymer that disintegrates overtime.(17)

Procedures for pelvic reconstruction utilizing native tissue are associated with a high recurrence rate.(12-14) This treatment failure can be attributable to the technique or defect in native tissues. Scarring and sclerosis produced by the standard pelvic reconstructive surgical procedures can restore only $50 \%$ of the preoperative tissue strength.(15) Reduced amount of collagen in connective tissue matrices in Stress Urinary Incontinence (SUI) women compared to unaffected women has been demonstrated. Data suggests that the process responsible for reduced collagen content in the tissues of women with SUI is not limited to the pubocervical fascia, but represents a systemic process detectable in tissues not involved in support of pelvic organs. Collagenase activity in the conditioned media from skin and pubocervical fascia biopsy explant cultures is higher in biopsies taken from women with SUI; that circulating collagenolytic activity is higher in women with SUI and that urinary levels of collagen degradation products are higher in women with SUI, all provide supportive evidence for increased collagenolysis in the aetiology of SUI.(16) Hence, in a recently published randomized control trial, recurrences of anterior vaginal prolapse were higher in the colporrhaphy group vs. reinforcement by mesh

In treating any patient with urinary incontinence, the goal is to provide the patient with a cure from her symptoms and improve her quality of life. To obtain this goal consistently, considering the variability among patients and the multiple factors contributing to the development of incontinence, physicians must be well aware of the various treatment options and their indications. Suburethral sling procedures have long been a mainstay in the surgical treatment for female stress urinary incontinence.

Traditionally, suburethral sling procedures were reserved for patients with recurrent stress urinary incontinence. During the past century, indications have been expanded to include not only those patients with the severe form of stress urinary incontinence, namely Intrinsic Sphincter Deficiency (ISD), but also patients with routine stress incontinence in conjunction with comorbid conditions.

With hopes of improving the treatment of stress incontinence symptoms, interest in primary and secondary slings has increased. The sling procedure is now often considered in any patient with stress urinary incontinence. The suburethral sling procedure requires careful attention to patient selection, workup, surgical technique and avoidance of complications.

Pelvic Organ Prolapse (POP) and Stress Urinary Incontinence (SUI) coexist in up to 80 percent of women with pelvic floor dysfunction. $(1,12)$ While these conditions are often concurrent, one may be mild or asymptomatic. Women without symptoms of SUI who undergo surgery for prolapse are at risk for postoperative urinary incontinence.(13) SUI may also worsen after prolapse repair.

Deciding whether to perform a combined surgical procedure to treat both prolapse and SUI or a single procedure that addresses only one condition requires balancing the risk of incomplete treatment with the risk of exposing the patient 
to unnecessary surgery.(14) This decision must be based on the best approach to address the patient's goals rather than simply on anatomic correction.(15,16) The rate of concurrent prolapse repair and continence procedures appears to be increasing. Data from the United States National Inpatient sample showed that for apical prolapse repair procedures, the rate of concurrent continence surgery increased from 38 percent in 2001 to 47 percent in 2009.(17)

Challenges in surgical decision-making in this clinical context include appropriate assessment of results of preoperative evaluation, some of which may be ambiguous (e.g. prolapse noted on examination in a patient with no prolapse-related symptoms or a patient with advanced prolapse with no leakage on prolapse reduction testing).

\section{Principle of Meshplasty}

Recent advances in mechanism of SUI show that the support at the mid-urethral level is weak resulting into sagging of midurethra. Thus for any reason increased pressure in urinary bladder and proximal half of urethra, more than that in midurethra results in dribbling or stress incontinence of urine with increased intra-abdominal pressure. So the weak or torn peri-urethral fascia is given support with synthetic material i.e. polypropylene mesh for permanent solution for this problem of stress incontinence. The polypropylene mesh gives mechanical support at the place where the pubocervical fascia is torn and gets interpenetrated by fibrous tissue leading to a tough scar and gives support to mid-urethra. $(17,18,19)$

\section{RESULTS}

Out of total 50 patients, in 24 patients NDVH with meshplasty was done. AP repair with meshplasty was done in 20 patients, 2 patients underwent vaginal hysterectomy with meshplasty and 4 patients underwent meshplasty alone. There were no intraoperative complications in the form of bladder injury, urethral injury, haemorrhagic shock, etc. Technically, meshplasty is a very simple procedure requiring less expertise as compared to TOT, TVT. Meshplasty takes very less time about 10 to 15 minutes. Five patients presented with $\mathrm{c} / \mathrm{o}$ burning micturition and urine R/E revealed UTI. Patients were given treatment to which they responded. No patient reported failure or recurrence of symptoms till date.

However, one patient reported with symptoms of mesh erosion like burning maturation, severe dysuria not responding to treatment. The patient was advised cystoscopy, but she refused and insisted on mesh removal. In this patient, mesh removal was done 4 months after meshplasty (Her initial surgery was NDVH with meshplasty). The mesh was removed after careful dissection and there was no injury to bladder or urethra.

\section{CONCLUSION}

Surgical treatment of stress incontinence has undergone lot of revolutionization the start of Kelly's plication sutures (With 30 to $40 \%$ success rate) to placement of synthetic mesh at mid urethral level with $90 \%$ and above success rate. In this procedure no intraoperative complications like haemorrhage, injury to bladder or urethra were noted. Also in this procedure assistance from other specialties like Urology is not required. This surgery can be performed along with other ancillary surgeries for pelvic floor defect repair; can be performed in patients with systemic diseases like hypertension, diabetes and heart disease, where local anaesthesia is of choice. Hospital stay is short depending upon the procedure, i.e. one to maximum three days. It is also a very cost effective procedure overall. Comparatively meshplasty is simple, technically easy to perform, safe and effective does not require much expertise and instruments, so can be performed at remote areas where we do not have much medical infrastructure. However, more studies on more number of patients are needed with long-term follow-up of these cases to exactly establish the importance of this procedure.

\section{REFERENCES}

1. Wall LL. Urinary stress incontinence. In: Rock JA, Thompson JD, eds. Te Linde's Operative Gynaecology. Philadelphia, Lippincott William and Wilkins, 1997; 9 th edn:1071.

2. Kokanali MK, Doganay M, Aksakal O, et al. Risk factors for mesh erosion after vaginal sling procedure for urinary stress incontinence. Eur J obstet Gynaecol Reprod Biol 2014;177:146-50.

3. Schierlitz L, Dwyer PL, Rosawilia A, et al. Pelvic organ prolapse surgery with an without tension free vaginal tape in women with occult or symptomatic urodynamic stress incontinence, a randomized controlled trial. Int Urogynaecol J 2014;25(1):33-40.

4. Takahashi S, Obinata D, Sakuma T, et al. Transvaginal mesh (TVM) reconstruction with TVT/TOT sling for vaginal prolapse concurrent with stress urinary incontinence. A Ktuelle urol 2010;41(1):S20-3.

5. Adyin S, Arioglu Aydin C. Effect of concomitant incision vaginal surgery on mid urethral sling success. Neurourol Urodyn 2015. Doi: 10.1002/nau.22847.

6. Chung E, Tse V, Chan L. Mid-uretheral synthetic slings in the treatment of urodynamic female stress incontinence without concomitants pelvic prolapse repair: 4 year health related quality of life outcomes. BJU Int 2010;105(4):514-7.

7. Navneet M, Kalra B, Malik S, et al. Stress urinary incontinence: what, when, why, and then what? J Midlife Health 2011;2(2):57-64.

8. Nygaard IE, Heit M. Stress urinary incontinence. Obstet Gynaecol 2004;104(3):607-20.

9. Romero Maroto J, Prieto Chaparro L, Lopez C, et al. Prolene mesh sling in the treatment of stress urinary incontinence. Integral treatment of pelvic floor anomalies. Long-term results. Arch Esp Urol 2002;55(9):1057-74.

10. Colombo M, Vitobello D, Proietti, et al. Randomised comparision of burch colposuspension $\mathrm{v} / \mathrm{s}$ anterior colporraphy in women with SUI and anterior vaginal wall prolapse. BJOG 2000;107:544-51.

11. Kane AR, Nager CW. Midurethral sling for stress urinary incontinence. Clin obstet gynaecol 2008;51(1):124-35.

12. Castellier C, Doucede G, Debodinanance P. Place of the mini-sling in the treatment of female stress incontinence. J Gynaecol obstet Biol Repord (Paris) 2013;42(7):63946.

13. Bezerra CA, Bruschini H. Sub urethral operations for urinary incontinence in women. Cochrane Database Syst Rev 2001;(3):CD001754. 
14. Serey-Eiffel S, Coquet JB, Fournier G, et al. Outpatient suburetheral sling in women, review of literature. Prog urol 2015;25(17):1204-12.

15. Ogah J, Cody JD, Rogerson L. Minimally invasive synthetic suburethral sling operations for stress urinary incontinence in women. Cochrane database syst Rev 2009;7(4):CD006375.

16. Vander Ploeg JM, Vander Steen A. Prolapse surgery with or without stress incontinence surgery for pelvic organ prolapse: a systemic review and meta-analysis of randomized trials. BJOG 2014;12(5):537-47.
17. Groutz A, Gordon D, Keidar R, et al. Stress urinary incontinence: prevalence and nulliparous compared with primiparous and grand multiparous premenopausal women. Neuro Urol Urodyn 1999;18(5):419-25.

18. Leach GE, Sirls L. Pubovaginal sling procedure. Atlas Urol Clin North Am 1994;2:61-71.

19. Ulmsten U, Falconer C, Johnson P, et al. A multicenter study of tension free vaginal tape (TVT) for surgical treatment of stress urinary incontinence. Int Urogynaecol J pelvic floor defect 1998;9(4):210-3. 